\title{
Basic Study on the Generation of RF Plasmas in Premixed Oxy-combustion with Methane
}

\author{
Yugo OSAKA, Noriyuki KOBAYASHI ${ }^{1)}$, M. A. RAZZAK ${ }^{2)}$, \\ ${\text { Noriyasu } \mathrm{OHNO}^{1)} \text {, Shuichi TAKAMURA }}^{3)}$ and Yoshihiko UESUGI ${ }^{4)}$ \\ Department of Chemical Engineering, Graduate School of Engineering, \\ Nagoya University, Furo-cho, Chikusa-ku, Nagoya 464-8603, Japan \\ ${ }^{1)}$ EcoTopia Science Institute, Nagoya University, Furo-cho, Chikusa-ku, Nagoya 464-8603, Japan \\ ${ }^{2)}$ Department of Energy Engineering and Science, Graduate School of Engineering, \\ Nagoya University, Furo-cho, Chikusa-ku, Nagoya 464-8603, Japan \\ ${ }^{3)}$ Department of Electrical and Electronics Engineering, Graduate School of Engineering, \\ Aichi Institute of Technology, Yakusa-cho, Toyota 470-0392 \\ ${ }^{4)}$ Department of Electrical and Electronic Engineering, Graduate School of Natural Science, \\ Kanazawa University, Kakuma-cho,Kanazawa 920-1192, Japan
}

(Received 7 May 2009 / Accepted 1 December 2009)

\begin{abstract}
Oxy-combustion generates a high temperature field (above $3000 \mathrm{~K}$ ), which is applied to next generation power plants and high temperature industrial technologies because of $\mathrm{N}_{2}$ free processes. However, the combustion temperature is so high that the furnace wall may be fatally damaged. In addition, it is very difficult to control the heat flux and chemical species' concentrations because of rapid chemical reactions. We have developed a new method for controlling the flame by electromagnetic force on this field. In this paper, we experimentally investigated the power coupling between the premixed oxy-combustion with methane and radio frequency (RF) power through the induction coil. By optimizing the power coupling, we observed that the flame can absorb RF power up to $1.5 \mathrm{~kW}$. Spectroscopic measurements also showed an increase in the emission intensity from $\mathrm{OH}$ radicals in the flame, indicating improved combustibility.
\end{abstract}

(c) 2010 The Japan Society of Plasma Science and Nuclear Fusion Research

Keywords: oxy-combustion, plasma assisted combustion, RF inductive plasma

DOI: $10.1585 /$ prr.5.010

\section{Introduction}

Combustion is a chemical reaction that generates a huge amount of heat formation. This chemical reaction continues voluntarily through active species. In industrial plants, high temperature exothermic reactions are applied widely, and are generated by the oxidation reaction of hydrocarbon and air. Air combustion generates large amounts of $\mathrm{NO}_{\mathrm{X}}$ because there is much $\mathrm{N}_{2}$ in the air. It is very difficult to separate $\mathrm{CO}_{2}$ from the combustion exhaust gas because the mole fraction of $\mathrm{CO}_{2}$ is much smaller than those of $\mathrm{N}_{2}$ and $\mathrm{NO}_{\mathrm{X}}$.

In our studies, we focus on oxy-combustion that uses only $\mathrm{O}_{2}$ or high concentrations of $\mathrm{O}_{2}$ as an oxidant. Oxycombustion has many advantages over air combustion. It can make a high temperature flame (above $3,000 \mathrm{~K}$ ). The mole fraction of $\mathrm{CO}_{2}$ in the exhaust gas from oxycombustion is much higher than in air-combustion because of nitrogen-free combustion. The separation and recovery of $\mathrm{CO}_{2}$ after oxy-combustion is much easier than after air combustion. Most of the exhaust gas in oxy-combustion is radiative gas such as $\mathrm{CO}_{2}$ and $\mathrm{H}_{2} \mathrm{O}$ which absorbs infrared

author'se-mail: y-osaka@ees.nagoya-u.ac.jp light emission [1]. It is possible to apply not only convective heat exchange but also radiational heat exchange in oxy-combustion.

Oxy-combustion plays an important role in revolutionary energy conversion technology or melting technology, for example, MHD (MagnetoHydroDynamic) power generation [2]. However various technological problems arise in oxy-combustion because its characteristics differ from the those of air-combustion [7-9]. The combustion temperature is high enough to fatally damage the furnace wall. In addition, in oxy-combustion, it is difficult to control the flame and the concentration of chemical species, for example $\mathrm{NO}_{X}$, because of rapid chemical reactions [3-6]. A new burner must be developed to solve these problems. The furnace wall should be detached from the high temperature flame by controlling the flow of the high temperature combustion field. The flame can be controlled by gas flow rates. We propose an alternative method to control the flame by applying an electromagnetic field to the flame in terms of the thermal plasma. It is thought that harmful chemical species such as $\mathrm{NO}_{\mathrm{X}}$ can be reduced if non-equilibrium plasma can be generated in a high temper- 


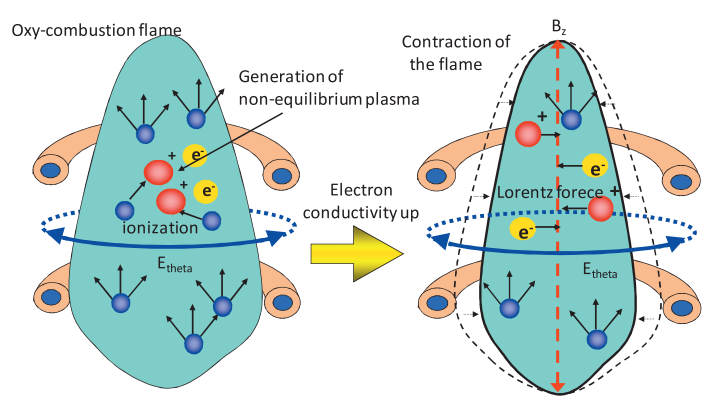

Fig. 1 Conceptual scheme of the high-temperature combustion control system.

ature combustion field. If these problems can be solved, oxy-combustion can be used in a wide range of applications. We have controlled the flow in this field as a thermal fluid.

There are many activated chemical species, some can be ionized to become charged particles (ions and electrons) due to thermal ionization. The combustion flame has weak electric properties. H.F. Calcote clarified that charged particles exist in the combustion flame [7]. Various studies on charged particles in a combustion field have been performed [8-12]. Oxy-combustion produces a very high temperature flame, which enhances thermal ionization, producing high density plasma in the flame. The combustion fluid has not only the characteristics of a thermal fluid but also those of a plasma fluid. We propose a new method to control high temperature flame by using the RF inductive plasma. Figure 1 shows a conceptual drawing of the high temperature combustion control method.

We produce plasmas by applying a RF power to the oxy-combustion flame. RF induction current is induced in the flame through the induction coil which is located a small distance from the flame. Plasma generation develops the electrical conductivity of the oxy-combustion flame. An inward Lorentz force, due to the inductive current and induced axial magnetic field, acts on the flame. This Lorentz force can contribute to detaching the flame from the furnace wall. In addition, we may be able to control chemical species in the combustion gas, because electrons in the plasma change the kinetics of the chemical reaction. We call this "plasma-assisted combustion."

In this paper, we investigated RF power input to the oxy-combustion flame with methane. We conducted spectroscopic measurements using an ICCD camera to observe the effect of RF power input on radicals' emission.

\section{Experimental Procedure}

Figure 2 shows a schematic drawing of the experimental setup with $1.0 \mathrm{MHz}$ RF power applied to an oxycombustion flame. Figure 3 shows the induction coil and oxy-combustion flame with methane. Methane and oxygen gas are employed in this experiment. The premix burner

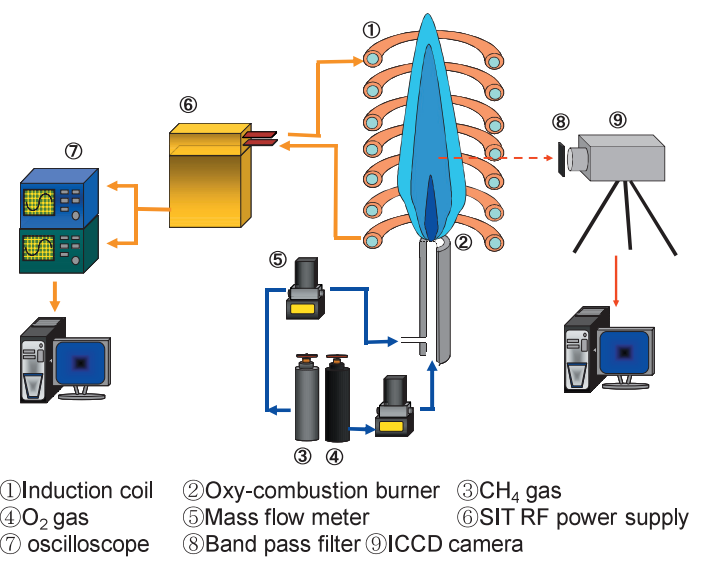

Fig. 2 Schematic drawing of the experimental set up of $1.0 \mathrm{MHz}$ RF power applied to oxy-combustion flame.

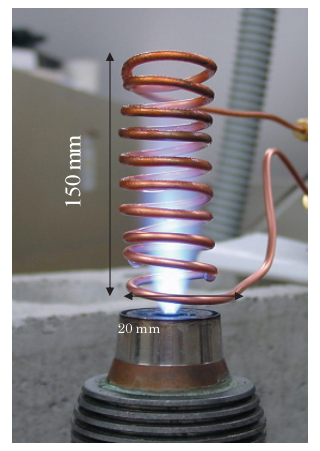

Fig. 3 Induction coil and oxy-combustion flame with methane.

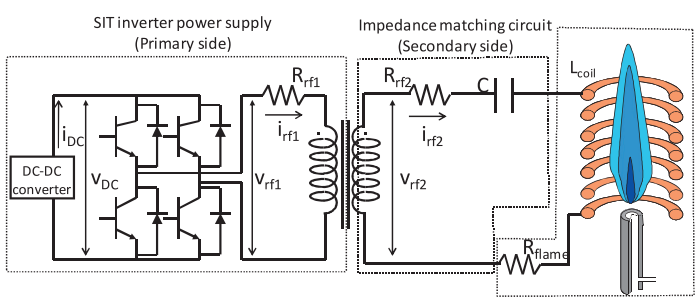

Fig. 4 Experimental circuit of SIT inverter power supply.

is made of brass, and has a diameter of $5.0 \mathrm{~mm}$. An aircooling fin is attached at the side of this burner to prevent overheating. The methane load is $1.8 \mathrm{~kW}_{\text {-LHV }}$, and the equivalent ratio is 1.0. (In other words, the gas flow rate of the methane is $3.0 \mathrm{sLPM}$, and that of the oxygen is 6.0 sLPM.)

Figure 4 shows a circuit diagram of SIT (static induction transistor) inverter power supply matching network and RF induction coil. Table 1 shows the specifications of the SIT inverter power supply. A DC voltage is fed to the SIT inverter unit from a DC-DC converter, having a maximum voltage and current of $400 \mathrm{~V}$ and $80 \mathrm{~A}$, respectively. The impedance matching circuit consists of a capacitor bank and an induction coil. The capacitance of the 
Table 1 Specification of SIT inverter.

\begin{tabular}{|l|l|}
\hline Output in a continuous run & $14 \mathrm{~kW}$ \\
Output in a pulse run & $20 \mathrm{~kW}$ \\
Operating frequency & $0.2 \sim 1.7 \mathrm{MHz}$ \\
Input direct voltage $: v_{\mathrm{DC}}$ & $400 \mathrm{~V}$ \\
Input direct current $: i_{\mathrm{DC}}$ & $90 \mathrm{~A}$ \\
\hline
\end{tabular}

capacitor bank is $4.0 \mathrm{nF}$. We turned the drive frequency of the SIT power supply to have a maximum coil current at the series resonance of the induction coil circuit. The range of the drive frequency of the SIT power supply is from $0.5 \mathrm{MHz}$ to $1.5 \mathrm{MHz}$. The induction coil has 14 turns, and is made of $1 / 8$ inch copper tubing that is $20 \mathrm{~mm}$ in diameter. Cooling water is fed through the copper tube to prevent melting of the coil. The typical duration of RF power input to the flame is $80 \mathrm{msec}$.

To observe the effect of RF power input on the flame, we conducted spectroscopic measurements using an ICCD camera with a band-pass filter and measured the loading impedance.

In the spectroscopic measurements, we use an ICCD camera capable of 4,500 fps. The time evolution of the emission intensities from $\mathrm{OH}$ radicals $(\lambda=307.2 \pm$ $12.5 \mathrm{~nm}$ ) was observed.

In loading impedance measurements, the primary circuit's voltage $v_{\mathrm{rf} 1}$, current $i_{\mathrm{rf} 1}$, and secondary circuit current $i_{\mathrm{rf} 2}$ were measured. The loading impedance $Z$ is calculated from the following formula:

$$
\begin{aligned}
& Z=\frac{P_{\mathrm{rf} 1}}{I_{\mathrm{rf} 2}^{2}} \\
& P_{\mathrm{rf} 1}=\frac{1}{T} \int_{0}^{T} v_{\mathrm{rf} 1}(t) \cdot i_{\mathrm{rf} 1}(t) \mathrm{dt}, \\
& I_{\mathrm{rf} 2}=\sqrt{\frac{1}{T} \int_{0}^{T} i_{\mathrm{rf} 2}(t) \mathrm{dt} .}
\end{aligned}
$$

We assumed the impedance transformer is an ideal one.

\section{Experimental Results and Discus- sions}

\subsection{Spectroscopic measurements}

We investigated the influence on the RF power input by using spectroscopic measurement with ICCD camera. We conducted optical spectroscopic measurement of the oxy-combustion flame with methane (from $300 \mathrm{~nm}$ to $800 \mathrm{~nm}$, resolution of this device is $1.0 \mathrm{~nm}$ ). Figure 5 shows the emission spectrum. The value of the vertical axis $I / I_{\mathrm{MAX}}$ is normalized by dividing the intensity $I$ by the maximum intensity $I_{\mathrm{MAX}}$. The continuous spectrum of

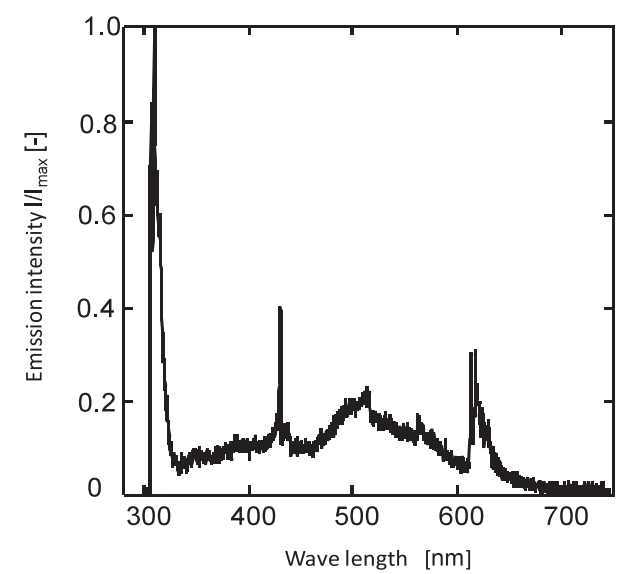

Fig. 5 Emission spectrum of oxy-combustion flame with methane.

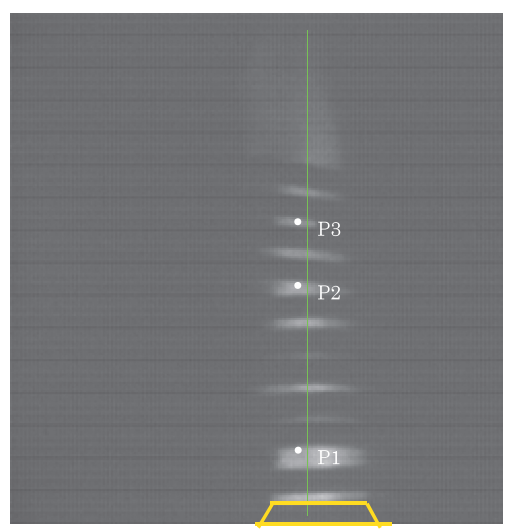

Fig. 6 Two-dimensional distribution of the emission intensity of $\mathrm{OH}$ radicals obtained using an ICCD camera and measurement position effect on the time evolution of emission intensity.

soot is small. This oxy-combustion has a blue flame due to premixed combustion. Thus, we confirmed that the generation of soot is not observed in this flame.

We investigated the effect of RF power input on $\mathrm{OH}$ and $\mathrm{CH}$ radicals. Figures 6 , and 7 show two-dimensional distributions of the emission intensity obtained using an ICCD camera. Time variations of the emission intensity for $\mathrm{OH}$ and $\mathrm{CH}$ radicals were measured at the positions marked P1, P2 and P3. ime variations of the emission intensity for $\mathrm{OH}(\mathrm{CH})$ radicals at $\mathrm{P} 1, \mathrm{P} 2$ and $\mathrm{P} 3$ specified in Fig. 6(7). We observed that the intensity of $\mathrm{OH}$ radicals obviously increases with RF power input. But from Fig. 9, that of $\mathrm{CH}$ radicals did not change. The absorption of RF power is thought to have had some influence as a result of the combustion reaction. The emission intensity of $\mathrm{OH}$ radicals mainly depends on the reaction rate of the expression (R1) below, and that of $\mathrm{CH}$ radicals depends on 


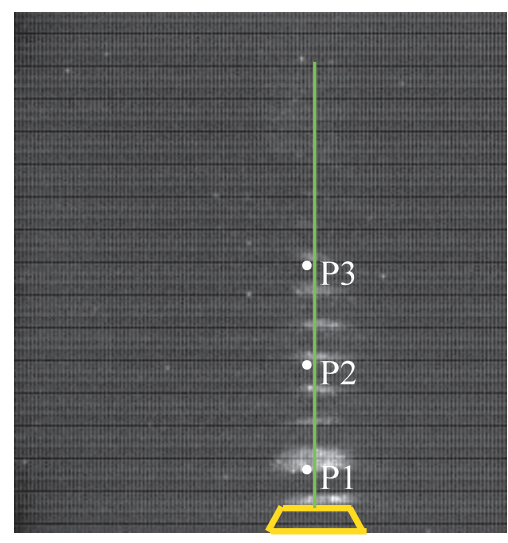

Fig. 7 Two-dimensional distribution of the emission intensity of $\mathrm{CH}$ radicals obtained using an ICCD camera and measurement position on the time evolution of emission intensity.

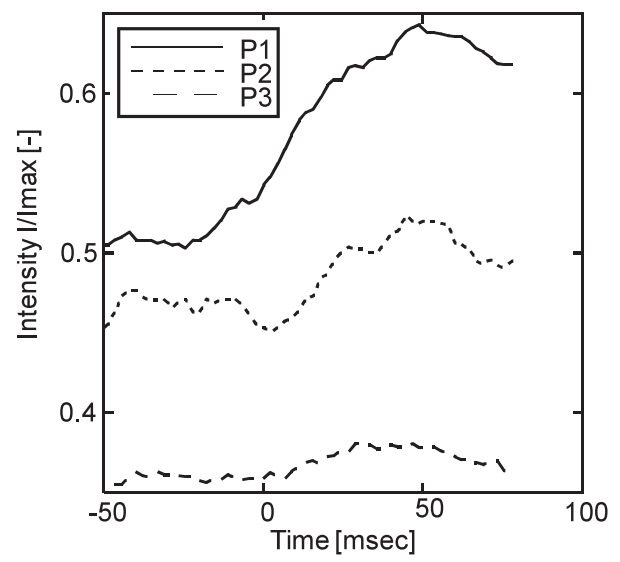

Fig. 8 Time variations of the emission intensity for $\mathrm{OH}$ radicals at P1, P2 and P3 specified in Fig. $6(\lambda=307.2 \pm 12.5 \mathrm{~nm})$.

(R2) $[13,14]$.

$$
\begin{aligned}
& \mathrm{CH}+\mathrm{O}_{2}=\mathrm{OH}^{*}+\mathrm{CO} \\
& \mathrm{OH}^{*}\left(\mathrm{~A}^{2} \Sigma^{+}\right) \rightarrow \mathrm{OH}^{*}\left(\mathrm{X}^{2} \Pi\right) \\
& \mathrm{C}_{2}+\mathrm{OH}=\mathrm{CH}^{*}+\mathrm{CO} \\
& \mathrm{CH}^{*}\left(\mathrm{~A}^{2} \Delta\right) \rightarrow \mathrm{CH}^{*}\left(\mathrm{X}^{2} \Pi\right)
\end{aligned}
$$

The emission intensity of $\mathrm{OH}$ radical depends on $[\mathrm{CH}]$ and the emission intensity of $\mathrm{CH}$ radicals is $\left[\mathrm{C}_{2}\right],[\mathrm{OH}]$. The increase in the emission of $\mathrm{OH}$ radical represents an increase in $[\mathrm{CH}]$, The increase in the emission of $\mathrm{CH}$ radicals represents an increase in $\left[\mathrm{C}_{2}\right]$. From Fig. 8, $\left[\mathrm{C}_{2}\right]$ did not increase with $\mathrm{RF}$ power input. We think that soot does not increase with $\mathrm{RF}$ power input. $[\mathrm{CH}]$ promotes the combustion reaction. In this spectroscopic measurement, we observed an increase in the emission intensity from $\mathrm{OH}$ radicals in the flame indicating improved combustibility.

This improvement is not obvious, so, further examination is needed to clarify it. If the combustibility is im-

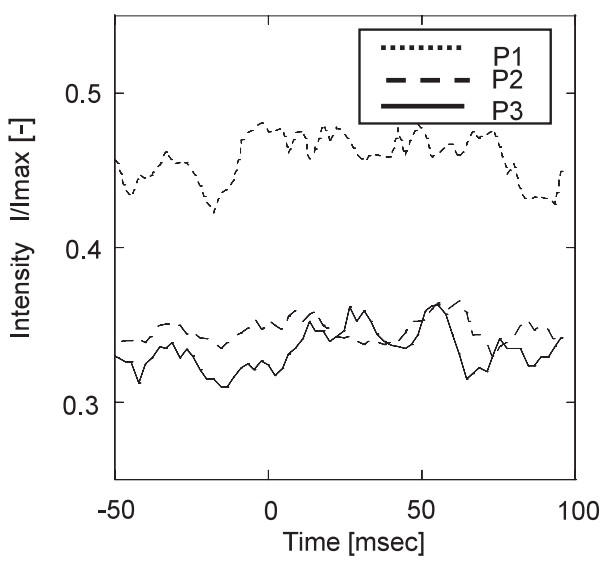

Fig. 9 Time variations of the emission intensity for $\mathrm{CH}$ radicals at P1, P2 and P3 specified in Fig. $7(\lambda=430.1 \pm 10 \mathrm{~nm})$.

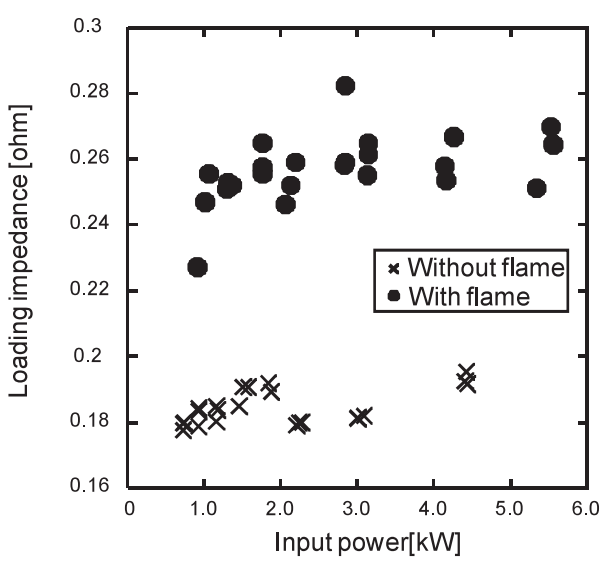

Fig. 10 Dependence of the loading impedance $Z$ on input power $P_{\text {rf1 }}$ with and without the flame.

proved by RF power input, non-equilibrium plasma might be generated.

\subsection{Measurement of the loading impedance}

Figure 10 shows the effect of RF power input on the loading impedance $Z$. We examined the influence of the coil diameter (i.d. $10 \mathrm{~mm}, 20 \mathrm{~mm}, 30 \mathrm{~mm}$ ). The RF induction current was largest in the vicinity of the coil. It is thought that RF power can be absorbed efficiently according to the RF induction current because the combustion flame exists in the region where the induction current is largest. In the experiment with a coil diameter of $10 \mathrm{~mm}$, the flow of the combustion flame was obstructed by the narrow coil. In contrast, a $30 \mathrm{~mm}$ coil diameter is too wide for the combustion flame. For these reasons, we could confirm only the result with the $20 \mathrm{~mm}$ diameter coil. From this result, we confirmed an obvious increase in loading impedance over the entire input power region in the experiment with a coil diameter of $20 \mathrm{~mm}$. No influence of the RF input power is observed. We think that the loading impedance is already saturated in the low power input 


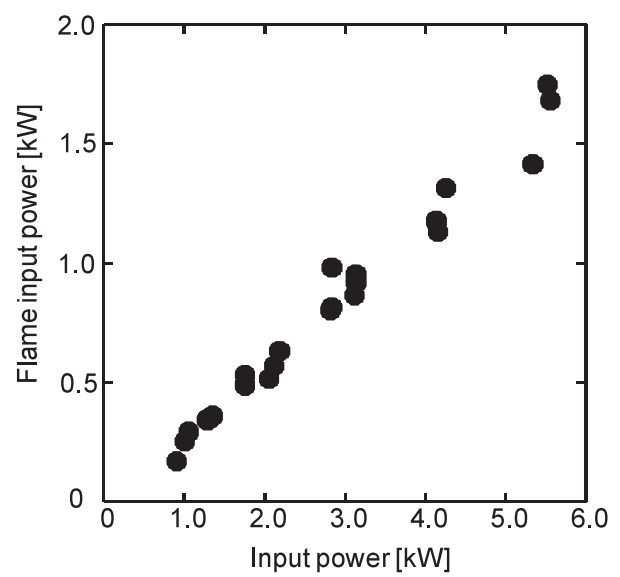

Fig. 11 Input power dependence of flame input power $P_{\text {flame }}$.

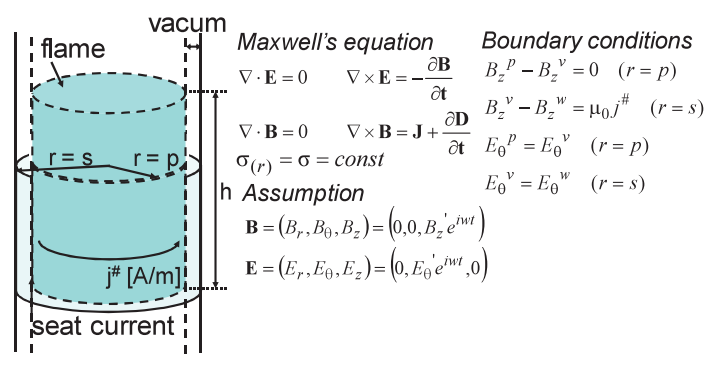

Fig. 12 Numerical model of ICP model.

region.

Figure 11 shows the flame input power $P_{\text {flame }}$ which is calculated from the following expression.

$$
P_{\text {flame }}=\frac{Z_{\mathrm{w} / \text { flame }}-Z_{\mathrm{w} / \text { oflame }}}{Z_{\mathrm{w} / \text { flame }}} \cdot P_{\mathrm{rf} 2} .
$$

It became clear that the flame input power $P_{\text {flame }}$ increased linearly against the input power, and showed maximum absorption at $1.5 \mathrm{~kW}$. The flow rate of methane is $3.0 \mathrm{sLPM}$, and the methane load is $1.8 \mathrm{~kW}_{\text {-LHV }}$. We confirmed that the flame input power and methane load are approximately the same. We could not visually confirm the effect on the flow of combustion gases, and Fig. 10, shows that the oxy-combustion flame could not absorb all the flame input power, because we do not get synchronization with the combustion flame in this device. In our future work, we have to develop a method that can absorb RF power into a combustion flame.

\subsection{Estimation of the electron conductivity}

To observe the influence of RF power input, we estimated the electron conductivity of the oxy-combustion flame by the ICP (Inductively Coupled Plasma) model shown in Fig. 12. Here, $p$ is the plasma radius, $s$ is the radius of the current sheet, and $j$ is the current density of the plasma sheet surrounding the plasma. We use the fol-

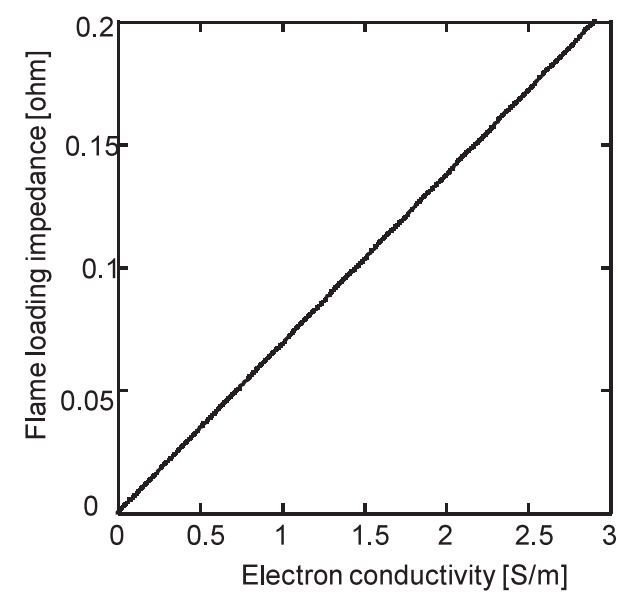

Fig. 13 Estimation of the electron conductivity of oxycombustion using the ICP model.

lowing basic equations (Maxwell's equations).

$$
\begin{aligned}
& \nabla \cdot \boldsymbol{E}=0, \\
& \nabla \times \boldsymbol{E}=-\frac{\partial \boldsymbol{B}}{\partial \boldsymbol{t}}, \\
& \nabla \cdot \boldsymbol{B}=0, \\
& \nabla \times \boldsymbol{B}=\boldsymbol{J}+\frac{\partial \boldsymbol{D}}{\partial \boldsymbol{t}} .
\end{aligned}
$$

We assume the following boundary conditions.

(1) The induction coil has infinite length in the $z$ direction.

(2) The coil current in the $\theta$ direction is uniform.

(3) Plasma conductivity is uniform in the $z$ direction.

(4) The electric field has only the $\theta$ direction component.

(5) The electron conductivity of the flame is uniformly distributed.

(6) The RF input power of the flame is all inductively.

The boundary conditions and assumptions are expressed in the following formulas.

$$
\begin{aligned}
& B_{z}^{p}-B_{z}^{v}=0 \quad(r=p), \\
& B_{z}^{v}-B_{z}^{w}=\mu_{0} j^{\#} \quad(r=s), \\
& E_{\theta}^{p}=E_{\theta}^{v} \quad(r=p), \\
& E_{\theta}^{v}=E_{\theta}^{w} \quad(r=s), \\
& \mathbf{B}=\left(B_{r}, B_{\theta}, B_{z}\right)=\left(0,0, B_{z}^{\prime} e^{i w t}\right), \\
& \mathbf{E}=\left(E_{r}, E_{\theta}, E_{z}\right)=\left(0, E_{\theta}^{\prime} e^{i w t}, 0\right), \\
& \sigma_{(r)}=\sigma=\text { const. }
\end{aligned}
$$

$E$ is the electric field, $B$ is the magnetic flux density, $D$ is the electric flux density, $j$ is the current density, and $\mu_{0}$ is the permittivity.

By using the above boundary conditions and Maxwell's equations, we estimated the conductivity of the oxy-combustion flame. The result is shown in Fig. 13. From Fig. 10, we can confirm that the increase in loading impedance of the oxy-combustion flame is $0.08 \Omega$. In this result and Fig. 7, we estimated the conductivity of the oxycombustion flame as $10^{0} \mathrm{~S} / \mathrm{m}$. We have also experimentally 


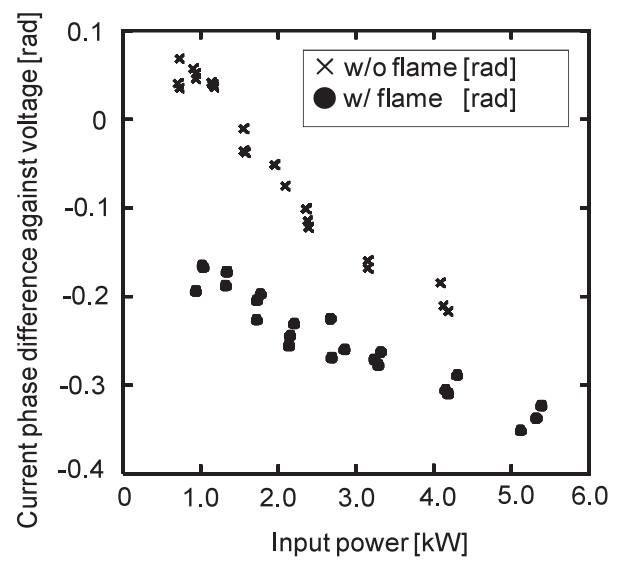

Fig. 14 Input power dependence of current phase difference against voltage.

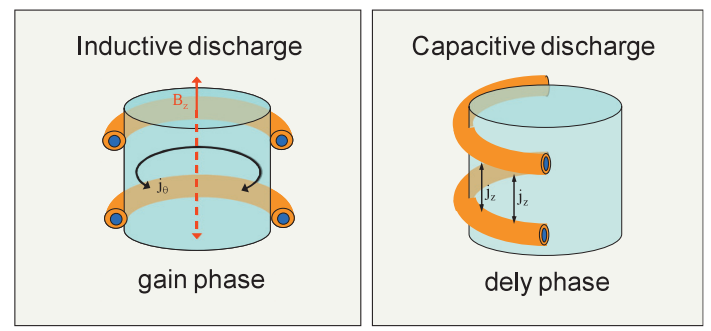

Fig. 15 Conceptual drawing of the discharge form.

measured the electron conductivity of the oxy-combustion flame by a double probe method [15], which showed that the conductivity of the oxy-combustion flame is approximately $10^{-4} \mathrm{~S} / \mathrm{m}$. This result differs greatly from the calculated result. In the ICP model, we examined some assumptions. In the double probe method, we directly measured the conductivity of the oxy-combustion flame. We considered the difference in the results in terms of the current phase difference against voltage, which is shown in Fig. 14. From the current phase difference against voltage, we can consider the discharge form of the oxy-combustion with RF power input because it expresses the difference in the coil reactance. Figure 15 shows a conceptual drawing of the discharge form. If the current phase is delayed against voltage phase, the discharge form is capacitive discharge. If the current phase gains against voltage phase, the discharge form is inductive discharge. From Fig. 14, it is seen that the discharge is dominantly capacitive. The calculation of the electron conductivity of oxy-combustion is higher than that of the experimental results using the double probe method because we assumed that the dominant discharge form is inductive discharge. Inductive discharge is preferable in terms of realizing our proposed method.
We need to consider a more effective discharge method than the usual one.

We need to develop other methods of probe measurement, etc., to confirm the generations of non-equilibrium plasma in the future. The RF induction current depends on the frequency. The higher the frequency is, the more the RF induction current grows. A higher frequency device is needed to absorb the RF power.

\section{Conclusion}

We proposed a new control method of oxycombustion by using plasma-assisted combustion to apply oxy-combustion to industrial power plants. We confirmed whether the combustion flame was able to absorb the RF induction power through the induction coil. We conducted spectroscopic measurements to confirm the generation of non-equilibrium plasma. The following knowledge was obtained from this study.

- In the experiment examining the effect of the RF induction power on the flame through the coil $(d=$ $20 \mathrm{~mm}$ ), we confirmed that the loading impedance was increased by RF induction power from the low input power region. The absorption of the RF induction power by the combustion flame was thus confirmed.

- From spectroscopic measurement of $\mathrm{OH}$ and $\mathrm{CH}$ radicals, we confirmed an increase in the emission intensity of $\mathrm{OH}$ radicals. That the possibility that nonequilibrium plasma is generated is thought to be high because of the improved combustibility.

- In the estimation of electron conductivity of oxycombustion using an ICP model and the results of current phase measurements, the calculated electron conductivity of oxy-combustion is higher than experimental results using a double probe method. Capacitive discharge is clearly dominant.

[1] S.V. Naik, Combust. Flame 134, 425 (2003).

[2] V.R. Malghan, Energy Convers. Manege. 37, 569 (1996).

[3] Y.Q. Hu et al., Energy Convers. Manage. 44, 2331 (2003).

[4] D. Poirier et al., IFRF Combustion Journal No 200404, 1 (2004).

[5] Y.Q. Hu et al., Fuel 79, 1925 (2000).

[6] A. Beltrame et al., Combust. Flame 124, 295 (2001).

[7] H.F. Calcote, Combust. Flame 1, 385 (1957).

[8] T. Pendersen et al., Combust. Flame 94, 433 (1993).

[9] A.N. Hayhurst et al., Combust. Flame 31, 37 (1978).

[10] C.S. Maclatchy, Combust. Flame 36, 171 (1979).

[11] J.M. Goodings et al., Combust. Flame 36, 27 (1979).

[12] R.M. Clements et al., J. appl. phys. 40, 4553 (1969).

[13] B.H. Higgins et al., Fuel 80, 67 (2001).

[14] J. Kojima et al., Combust. Flame 140, 34 (2005).

[15] Y. Osaka et al., Contrib. Plasma Phys. 48, 485 (2008). 